\title{
GAMBARAN VISUS MATA PADA SENAT MAHASISWA FAKULTAS KEDOKTERAN UNIVERSITAS SAM RATULANGI
}

\author{
${ }^{1}$ Freelyn Ch. P. Tamboto \\ ${ }^{2}$ Herlina I. S. Wungouw \\ ${ }^{2}$ Damajanty H. C Pangemanan
}

\author{
${ }^{1}$ Kandidat Skripsi Fakultas Kedokteran Universitas Sam Ratulangi Manado \\ ${ }^{2}$ Bagian Fisiologi Fakultas Kedokteran Universitas Sam Ratulangi Manado \\ Email: freelynchristo@gmail.com
}

\begin{abstract}
Visus is visual acuity. Vision examination is an examination to see visual acuity. Overview vision and blindness remains a substantial social problem in Indonesia. WHO estimates that in 2000 there were 45 million people with blindness in the world, in which one third is in south east asia. With the world's population increases with the increase in life expectancy will increase the number of blindness at least one million people Indonesia reached $1.47 \%$. This study aims to determine visual acuity eye on the students of the Faculty of Medicine, University of Sam Ratulangi. This descriptive study using cross sectional study design (cross-sectional). With the study sample met the criteria is the age of 19-22 years old and healthy while doing research. The samples were students of the Faculty of Medicine, University of Sam Ratulangi numbered 20 people. Based on the research results that show the frequency of eye vision disorders did not differ between the sexes men and women, but the effect on the frequency of vision disorder age. Conclusion: Impaired vision usually occurs due to hereditary factors or behavioral factors that are not well when reading or watching near for a long time and with less lighting.
\end{abstract}

Keywords: visus

\begin{abstract}
Abstrak: Visus adalah ketajaman penglihatan. Pemeriksaan visus merupakan pemeriksaan untuk melihat ketajaman penglihatan. Gambaran penglihatan dan kebutaan masih menjadi masalah sosial yang cukup besar di Indonesia. WHO memperkirakan pada tahun 2000 terdapat 45 juta penderita kebutaan di dunia, di mana sepertiganya berada di Asia Tenggara. Penambahan jumlah penduduk dunia dengan peningkatan umur harapan hidup maka jumlah kebutaan akan meningkat paling sedikit satu juta orang Indonesia mencapai 1,47\%. Penelitian ini bertujuan untuk mengetahui visus mata pada mahasiswa Fakultas Kedokteran Universitas Sam Ratulangi. Penelitian ini bersifat deskriptif dengan menggunakan desain studi potong lintang (cross sectional study). Sampel penelitian yang memenuhi kriteria yaitu usia 19-22 tahun dan sehat disaat melakukan penelitian. Sampel penelitian adalah mahasiswa Fakultas Kedokteran Universitas Sam Ratulangi berjumlah 20 orang. Berdasarkan penelitian diperoleh hasil yang menunjukkan frekuensi gangguan visus mata tidak berbeda antara jenis kelamin laki laki maupun perempuan, namun frekuensi gangguan visus berpengaruh pada usia. Simpulan: Gangguan visus biasanya terjadi karena faktor herediter atau faktor perilaku yang tidak baik saat membaca atau nonton dekat dalama waktu yang lama dan dengan penerangan yang kurang.
\end{abstract}

Kata kunci: visus

Penglihatan dan kebutaan masih menjadi masalah sosial yang cukup besar di
Indonesia. Mata adalah panca indra penting yang perlu pemeriksaan dan perawatan 
secara teratur. Pemeriksaan rutin pada mata sebaiknya dimulai pada usia dini. Pada anak 2-2.5 tahun, skrining mata perlu dilakukan untuk mendeteksi apakah menderita gangguan tajam penglihatan yang nantinya akan mengganggu aktivitas disekolahnya pertahun ${ }^{1}$.

WHO memperkirakan pada tahun 2000 terdapat 45 juta penderita kebutaan di dunia, di mana sepertiganya berada di Asia Tenggara. Dengan pertambahan jumlah penduduk dunia dengan peningkatan umur harapan hidup maka jumlah kebutaan akan meningkat paling sedikit satu juta orang Indonesia mencapai 1,47\%. Angka kebutaan di Indonesia jauh lebih tinggi di bandingkan dengan angka kebutaan di Negara lain (Bangladesh 1,0\%, India 0,7\%, Thailand 0,3\%, Afrika Sub-Sahara 1,40\%). Angka kebutaan ini menurun menjadi 1,2\% berdasarkan survei kesehatan rumah tangga tahun $2001^{2}$.

Dari hasil Survei Depertemen kesehatan Republik Indonesia yang dilakukan di 8 provinsi (Sumatera Barat, Sumatera Selatan, Jawa Barat, Jawa Tengah, Jawa Timur, Sulawesi Utara, Sulawesi Selatan dan Nusa Tenggara Barat) tahun 1996 ditemukan kelainan refraksi sebesar $24.71 \%$ dan menempati urutan pertama dalam 10 penyakit mata terbesar di Indonesia $^{2 \& 4}$.

Jenis penyakit mata terus mengalami perkembangan baik dari segi faktor penyebab, teknik pengobatan, dan peralatan medis untuk penyembuhan, hingga keberadaan mitos penyakit mata itu sendiri. Gangguan penglihatan dan kebutaan menjadi tantangan serius parah ahli penyakit mata saat ini. gangguan penglihatan merupakan masalah kesehatan yang penting, terutama pada anak, mengingat $80 \%$, informasi selama 12 tahun pertama kehidupan anak di dapat melalui penglihatan. Penelitian sebelumnya dilakukan pada 479 siswa di Kabupaten Karangasem pada bulan Agustus 2008, 95\% mengalami kebutaan dan 4,6\% mengalami gangguan penglihatan parah. Data tersebut menunjukkan 35,9\% penyebab kebutaan atau gangguan penglihatan parah terletak pada bola mata, $18,9 \%$ pada retina, $16,4 \%$ pada lensa, serta $16,1 \%$ pada kornea, sebagian besar tidak diketahui penyebabnya, akan tetapi 31,9\% disebabkan pada faktor herediter ${ }^{3}$.

Cedera dan penyakit mata bisa mempengarui penglihatan. Kejernihan penglihatan bisa disebut ketajaman visus, yang berkisar dari penglihatan penuh sampai tampak penglihatan. Jika ketajaman menurun, pengihatan menjadi kabur. Ketajaman penglihatan biasanya diukur dengan skala yang membandingkan penglihatan seseorang pada jarak 6 meter dengan seseorang yang memiliki ketajaman penuh. Visus 6/6 artinya seseorang melihat benda jarak 6 meter dengan tajam penuh ${ }^{3}$.

\section{METODE PENELITIAN}

Visus adalah ketajaman penglihatan. Pemeriksaan visus merupakan pemeriksaan untuk melihat ketajaman penglihatan. Penelitian ini bersifat deskriptif dengan menggunakan desain studi potong lintang (cross sectional study).

\section{HASIL PENELITIAN}

Analisis data menunjukkan, bahwa dari 20 mahasiswa, terdapat jenis kelamin laki laki 10 mahasiswa (50\%) dan perempuan 10 mahasiswa (50\%). Dengan variasi umur 19-22 tahun. Sampel dibagi dua kelompok berdasarkan jenis kelamin dan umur. Kelompok pertama dengan 10 perempuan dan 10 laki laki, kelompok ke dua di bagi berdasarkan umur 19-22. Mahasiswa dengan umur 19 tahun sebanyak 5 orang (25\%), 20 tahun 5 orang (25\%), 21 tahun 5 orang (25), dan 22 tahun 5 orang(25\%).

Karakteristik subjek penelitian berdasarkan distribusi jenis kelamin dan umur dapat di lihat pada Tabel.

Pada Tabel 1 dapat dilihat frekuensi kejadian gangguan mata berdasarkan jenis kelamin. Dari data tersebut dapat disimpulkan frekuensi gangguan mata tidak berbeda antara jenis kelamin laki laki maupun perempuan. 
a. Karakteristik Menurut Jenis Kelamin

Tabel 1. Pemeriksaan visus berdasarkan jenis kelamin

\begin{tabular}{llll}
\hline $\begin{array}{l}\text { Jenis } \\
\text { kelamin }\end{array}$ & $\begin{array}{l}\text { Normal } \\
(\%)\end{array}$ & $\begin{array}{l}\text { Tidak } \\
\text { Normal } \\
(\%)\end{array}$ & $\begin{array}{l}\text { Total } \\
(\%)\end{array}$ \\
\hline Laki-laki & $7(35)$ & $3(15)$ & $10(50)$ \\
Perempuan & $6(30)$ & $4(20)$ & $10(50)$ \\
Total & $13(65)$ & $7(35)$ & $20(100)$ \\
\hline
\end{tabular}

b. Karakteristik Visus Berdasarkan Umur.

Karakteristik berdasarkan umur mahasiswa dengan umur 19 tahun sebanyak 5 orang (25\%), 20 tahun 5 orang (25\%), 21 tahun 5 orang (25), dan 22 tahun 5 orang(25\%) dengan total 20 orang (100\%).

Tabel 2. Pemeriksaan visus berdasarkan umur

\begin{tabular}{cccl}
\hline Usia & Frekuensi & $\begin{array}{c}\text { Normal } \\
(\%)\end{array}$ & $\begin{array}{c}\text { Tidak } \\
\text { normal (\%) }\end{array}$ \\
\hline 19 & 5 & $4(20 \%)$ & $1(5 \%)$ \\
20 & 5 & $4(20 \%)$ & $1(5 \%)$ \\
21 & 5 & $1(5 \%)$ & $4(20 \%)$ \\
22 & 5 & $1(5 \%)$ & $4(20 \%)$ \\
\hline Total & 20 & $50 \%$ & $50 \%$ \\
\hline
\end{tabular}

Pada Tabel 2 dapat disimpulkan frekuensi gangguan mata berpengaruh terhadap usia.

\section{BAHASAN}

Telah dilakukan penelitian cross sectional pada 20 orang mahasiswa yang bertujuan untuk mengetahui frekuensi kejadian gangguan visus di fakultas kedokteran universitas Sam Ratulangi Manado. Dari penelitian didapatkan hasil subyek dengan jenis kelamin laki-laki sebanyak 10 mahasiswa (10\%), dan subyek dengan jenis kelamin perempuan sebanyak 10 mahasiswa (10\%).

Pada penelitian ini, didapatkan 7 mahasiswa dengan gangguan visus dengan jenis kelamin laki-laki sebanyak 3 orang dan perempuan sebanyak 4 orang, namun tidak ditemukan perbedaan yang bermakna antara jenis kelamin dan kejadian kelainan visus dalam penelitian ini. Sedangkan pada perbedaan umur dapat di lihat bahwa usia berpengaruh pada ketajaman penglihatan.

Tajam penglihatan merupakan masalah kesehatan yang penting. Deteksi dini dan publikasi mengenai prevalensi dan faktor yang berhubungan dengan kelainan tajam penglihatan di Indonesia masih jarang dilakukan. sedangkan tajam penglihatan yang baik sangat diperlukan dalam proses belajar mengajar.

Mahasiswa dengan kondisi ketajaman mata kurang baik karena memiliki kebiasaan nonton lama, posisi membaca sambil tidur dengan pencahayaan yang kurang. Faktor lain yang menyebabkan visus mata kurang baik adalah faktor genetik dan faktor perilaku atau aktivitas melihat dekat dalam jangka waktu yang panjang, intensitas menggunakan komputer secara terus menerus, intensitas menonton tv secara terus menerus dan intensitas membaca buku secara terus menerus ${ }^{5}$.

Kerusakan yang terjadi saat membaca di tempat dengan penerangan lampu yang minim dibandingkan dengan di tempat terang, adalah keletihan mata. Profesor Howard Howland, seorang ahli Optometri dari Cornell University mengatakan bahwa saat membaca, otot meregang lebih banyak dibandingkan dalam keadaan normal. Hal ini terjadi agar semua yang ada di depan mata menjadi fokus. Kondisi mata yang letih ini sendiri bisa hilang hanya dengan mengistirahatkan mata untuk beberapa saat. Ahli optometri menyarankan agar setelah melihat hal-hal yang dekat selama 15 hingga 30 menit, kita seharusnya beristirahat selama satu menit dengan memandang kejauhan. Selain itu, hal yang amat membantu adalah memejamkan mata selama semenit, karena saat berfokus pada sesuatu yang dekat seperti membaca, biasanya hanya berkedip seperpempat kali lipat dari kondisi normal, hingga mata menjadi lebih kering. Orang yang seharusnya lebih banyak mendapat perhatian adalah mereka yang terfokus pada benda-benda yang dekat dalam jangka waktu yang lama. Contohnya orang yang bekerja menggunakan komputer sepanjang hari atau menjahit dengan mesin. Mereka memiliki risiko lebih besar mengalami 
rabun dekat ${ }^{5}$.

Untuk semua kelainan atau penyakit mata yang menyebabkan penurunan ketajaman penglihatan ada beberapa prosedur yang disarankan para ahli dalam penatalaksanaan-nya, yaitu Laser Thermal Keratoplasty (LTK), Photorefractife Keratectomy (PRK) dan LASIK ${ }^{6}$.

- Laser Thermal Keratoplasty (LTK)

Laser holmium: yttrium-aluminiumgarnet (Ho:YAG) merupakan laser yang mendapat izin FDA untuk laser thermal keratoplasty dengan panjang gelombang $2100 \mathrm{~nm}$ dan kedalaman penetrasi kornea 480-530 pm, yaitu sekitar 8090\% dari kedalaman kornea sehingga terhindar dari kerusakan endotel.

- Photorefraktive Keratektomi (PRK) Pada PRK, excimer laser diarahkan langsung mengablasi stroma kornea dan epitel untuk mengkoreksi kesalahan refraksi.

- LASIK (Laser In Situ Keratomileusis)

LASIK merupakan bedah refraksi yang popular saat ini dan dapat digunakan untuk mengobati hipermetrop derajat rendah sampai tinggi dengan hasil yang memuaskan. FDA merekomendasikan LASIK untuk koreksi hipermetrop sampai $+6.00 \mathrm{D}^{7}$.

\section{SIMPULAN}

Dari hasil penelitian dapat disimpulkan bahwa frekuensi kejadian gangguan visus pada mahasiswa dengan karakteristik umur 21 dan 22 tidak ada perbedaan bermakna antara kejadian kelainan refraksi berdasarkan jenis kelamin.

\section{DAFTAR PUSTAKA}

1. MENKES RI, 2006. Hasil Survei Kesehatan Indra Penglihatan Dan Pendengaran. Jakarta (Diakses 1 September 2015). Available from: http: //www.dinkesjatengprov.go.id/v2010/ dokumen/2014/SDK/Mibangkes/peru ndangan/BimaGizidanKIAKMKMan ajemen

KeshatanInderaPenglihatandanPende ngaran.pdf

2. DEPKES RI. 2003. Rencana Strategi Nasional Penanggulangan Penglihatan Dan Kebutaan (PGPK) Untuk Mencapai Vision 2020. Jakarta. Available from: http: //perpustakaan.depkes.go.id:8180/bits tream/123456789/1030/3/KMK14731005-G56.pdf

3. Fachrian. 2009. Prevalensi Kelainan Tajam Penglihatan Pada Pelajar Sd "X" Jatinegara Jakarta Timur. Jurnal Kedokteran Universitas Pembangunan Nasional. Jakarta. Available from: http://indonesia.digitaljournal.org/ind ex.php/idnmed/article/viewfile/646/6 41.

4. Selvarajah K. 2011. (Diakses 1 September 2015). Available from: http://thesis.umy.ac.id/datapublik/t19 889.pdf

5. National Geographic Indonesia. Benarkah Membaca Dalam Keremangan Merusak Mata [serial online]. 2015 [diakses 27 Oktober 2015]. Available from: http: //nationalgeographic.co.id/berita/2015 /05/benarkah-membaca-dalamkeremangan-merusak-mata\#

6. McGhee CN, Ormonde S, Kohnen T, Lawless M, Brahma A, Comaish I. The Surgical Correction of Moderate Hypermetropia: the Management Controversy. $\mathrm{Br} \mathrm{J}$ Ophthalmol. 2002;86:815-22.

7. Ilmu Penyakit Mata FK Unand, Penatalaksanaan Hipermetrop. 2007. (Diakses 1 September 2015). Available from: http://repository.unand.ac.id/1267/1/P enatalaksanaan_Hipermetrop.pdf. 